\title{
A Prática Discursiva das Altas Habilidades em Matemática
}

\section{The Discursive Practice of High Skills in Mathematics}

\author{
Karin Ritter Jelinek*
}

\begin{abstract}
Resumo
As pesquisas acerca das altas habilidades, via de regra, desenvolvem-se no campo da psicologia. Contudo, neste artigo, procura-se analisar a temática a partir de uma perspectiva pós-estruturalista. Partindo desse entendimento, as altas habilidades em matemática são um discurso que posiciona os sujeitos como portadores de altas habilidades e, assim, cabe analisar, conforme sugere Foucault, as práticas discursivas que colocam em circulação as verdades que constituem tais habilidades e seus sujeitos escolares. Dessa forma, este trabalho aborda as questões de normalização - embasadas em estratégias de poder-saber-verdade presentes nas práticas discursivas - que estão ligadas às atividades de identificação e enriquecimento educativo desses sujeitos escolares.
\end{abstract}

Palavras-chave: Altas habilidades. Discurso. Verdade. Norma.

\begin{abstract}
Research about high skills is being developed in the field of psychology. However, this paper aims to analyze this issue from a Post-Structuralist perspective. From this understanding, high skills in mathematics are a speech that positions the subject as a bearer of high skills, and thus, we can analyze, according to Foucault, the discursive practices that reproduce the truths which constitute such skills and their school subjects. For this reason, this paper addresses the issues of standardization - based in strategies of power/knowledge/truth that are presented in the discursive practices - that are linked

\footnotetext{
"Doutoranda em Educação pela Universidade Federal do Rio Grande do Sul (UFRGS). Professora do Instituto de Matemática, Estatística e Física da Universidade do Rio Grande (FURG), Rio Grande, RS, Brasil. Endereço para correspondência: Rua Paes de Andrade, 47, Menino Deus, CEP: 90160 230, Porto Alegre, RS, Brasil.E-mail: karinjelinek@furg.br.
} 
to the identification activities and educational enrichment of school subjects.

Keywords: High skills. Speech. Truth. Standard.

\section{Introdução}

As pesquisas acerca das altas habilidades desenvolveram-se comumente no campo da psicologia. Contudo, neste trabalho, analiso a temática a partir de uma perspectiva pós-estruturalista. O discurso das altas habilidades, assim como grande parte dos discursos, é composto por descontinuidades e atualizações. O presente artigo visa olhar para esse discurso e suas verdades, pelo fato de que o mesmo ressurge, atualmente, com uma força significativa nos ambientes escolares e a partir das políticas públicas voltadas à Educação.

A discussão proposta diz respeito a um novo olhar sobre o discurso das altas habilidades, utilizando-se para isso das ferramentas analíticas do pósestruturalismo, entendidas, aqui, como coloca Corazza (1998, p.2) "um conjunto de desenvolvimentos teóricos vinculados a uma determinada concepção do papel e da natureza da linguagem, do discurso, [...]"; mais especificamente, realizada com o auxílio de ferramentas foucaultianas.

Buscando entender quais são as condutas relacionadas a esses indivíduos e como se dá esse trabalho, toma-se emprestado um conceito-chave de Foucault: o discurso, o qual forma sistematicamente os objetos dos quais fala.

Chamaremos de discurso um conjunto de enunciados, na medida em que se apoiem na mesma formação discursiva; ele não forma uma unidade retórica ou formal, indefinidamente repetível e cujo aparecimento ou utilização poderíamos assinalar (e explicar, se for o caso) na história; é constituído de um número limitado de enunciados para os quais podemos definir um conjunto de condições de existência (FOUCAULT, 2008, p.132 - 133).

Poder identificar quais são as regras e as verdades que regem o discurso das altas habilidades, hoje, parece ser pertinente para que se compreenda como acontece o trabalho com tais educandos. Quando me refiro às verdades, concordo com Mosé quando ela afirma que "[...] não são as verdades que devem ser colocadas em questão, mas o próprio valor de verdade" (2005, p.71). Em outras palavras, penso que devemos procurar entender, fundamentalmente, quais as possibilidades para que tais verdades se constituam em um dado ambiente e não noutro. 
Os discursos são práticas regradas que se modificam, conforme se transformam também os enunciados ${ }^{1}$ - e as verdades que os constituem - e as configurações de saber de um dado momento histórico. Dessa forma, diferentes discursos se sobrepõem ao longo desses períodos de forma descontínua, porém, regular. Assim, podemos dizer que tais discursos se transformam à medida que as verdades e os valores que os constituem, dão forma, também se alteram, pois, de acordo com Machado (2002, p.85), nós é que produzimos as verdades, uma vez que os valores que as sustentam são históricos, sociais e produzidos.

Eles permitem que se fixem diferenças a partir de identidades entre os indivíduos e, consequentemente, que se fabriquem desigualdades. É a partir do próprio discurso - de suas enunciações, regularidades e descontinuidades - que podemos analisar as suas condições externas de possibilidades, ou ainda, a sua materialidade.

A partir dessa noção inicial, busco problematizar as ações que envolvem a seleção de crianças ditas portadoras de altas habilidades. Entendendo que existem regras de formação do conceito das altas habilidades, bem como das operações com ele executadas, direciono meu foco no entendimento do discurso como uma prática discursiva.

Esse redirecionamento faz-se necessário na medida em que se entende que as práticas discursivas "moldam nossa maneira de constituir o mundo, de compreendê-lo e de falar sobre ele" (VEIGA-NETO, 2007, p.93). Nas palavras de Foucault, entende-se como prática discursiva "[...] um conjunto de regras anônimas, históricas, sempre determinadas no tempo e no espaço, que definiram, em uma dada época e para uma determinada área social, econômica, geográfica ou linguística, as condições de exercício da função enunciativa" (2008, p.133).

As altas habilidades, neste estudo, são vistas como práticas discursivas, pois têm como prerrogativa regras e regularidades que pautam ações e constituem aquele que se entende como portador de altas habilidades e as práticas a ele relacionadas. Tal postura é assumida na medida em que Bello coloca que "[...] a suposição, por exemplo, que os discursos pedagógicos e alguns outros, fabriquem determinados tipos de práticas e, estas, enquanto práticas sociais produzam subjetividades, identidades, regras institucionais, assujeitamentos; é bastante pertinente" (2010, p.18).

\footnotetext{
${ }^{1}$ Os enunciados não são uma unidade elementar como a frase e a proposição, guiados pela gramática. Eles oferecem as condições de existência dos diferentes conjuntos significantes dos quais a frase e a proposição também fazem parte. "[...] caracteriza não o que nelas se apresenta ou a maneira pela qual são delimitadas, mas o próprio fato de serem apresentadas, e a maneira pela qual o são" (FOUCAULT, 2008, p.126).
} 
Nesse discurso, o sujeito das altas habilidades é uma produção discursiva e, para compreendê-lo, precisamos nos ater ao conjunto de regras que lhe dão forma. Assim, faz-se interessante, aqui, pensar como essa prática discursiva acerca das altas habilidades foi se construindo, tendo em vista que a mesma é composta por descontinuidades e (re)atualizações. Cabe explorar, então, as movimentações que envolvem as políticas educacionais, na sociedade civil e na produção científica. Inicialmente, cabe compreender como a legislação brasileira, enquanto prática discursiva, foi constituindo esse que estamos chamando de sujeito das altas habilidades.

Até a década de 80, o discurso que circulava nas instituições escolares diferenciava as crianças normais, dos ditos retardados ou superdotados. De acordo com Pérez e Freitas (2009), dentro do campo das políticas educacionais, nesse período emergiram apenas breves menções em alguns documentos oficiais. Na década de 60, observa-se apenas uma menção à necessidade de se garantir uma educação aos excepcionais ${ }^{2}$.

$\mathrm{Na}$ década de 70, é mencionado, pela primeira vez, o termo superdotado ${ }^{3}$, indicando que devem receber atendimento especial, de acordo com as normas fixadas pelos competentes Conselhos de Educação. Complementarmente, reconheceu-se, para esses alunos, a não existência de barreiras entre séries escolares, bem como a matrícula dos superdotados no ensino superior antes da conclusão do ensino médio ${ }^{4}$. Ainda nesse período, se deu a Criação do Centro Nacional de Educação Especial (CENESP) junto ao MEC, visando apontar ações educativas e financiar iniciativas ligadas aos indivíduos portadores de necessidades especiais.

Na década de 80, acontecem ações mais consistentes no âmbito político, pois o sujeito das altas habilidades passa a ser definido ${ }^{5}$ - porém ainda através do termo superdotado - e a ter características específicas relacionadas a ele ${ }^{6}$. Art. 3 [...] Superdotados: educandos que apresentam notável desempenho e/ou elevada potencialidade nos seguintes aspectos, isolados ou combinados: capacidade intelectual, aptidão acadêmica, pensamento criador, capacidade de liderança, talento especial para artes, habilidades psicomotoras, necessitando atendimento educacional especializado.

\footnotetext{
${ }^{2}$ Lei $n^{\circ} 4024$ - Lei de Diretrizes e Bases da Educação de 1961.

${ }^{3}$ Lei $n^{\circ} 5692$ - Lei de Diretrizes e Bases da Educação de 1971.

${ }_{4}^{4}$ Parecer no 255 e n ${ }^{\circ} 436$ de 1972; e parecer no 681 de 1973.

5 Portaria $n^{\circ} 69$ de 1986.

${ }^{6}$ Parecer 711/87 de 1987.
} 
Temos também a substituição do CENESP pela Secretaria de Educação Especial (SEESP), que publica os Subsídios para a organização $e$ funcionamento de serviços de Educação Especial, com volume dedicado à área da superdotação. Tem-se, assim, a constituição da noção de que existe a necessidade de um trabalho específico para esses indivíduos, o que é retificado pela criação das Diretrizes gerais para o atendimento educacional aos alunos portadores de altas habilidades/superdotação e talentos ${ }^{8}$.

Na década de 90, temos a construção da Declaração de Salamanca ${ }^{9}$, que é um documento internacional que dá o amparo legal para o atendimento do aluno com altas habilidades e, a nível nacional, temos o encontro para discussão e elaboração da Política Nacional de Educação Especial ${ }^{10}$ e a reedição das Diretrizes gerais para o atendimento educacional aos alunos portadores de altas habilidades/superdotação e talentos $^{11}$.

Também na década de 90, através dos estudos de Gardner, o discurso educacional passou a defender a existência de diferentes habilidades, de modo que cada indivíduo sempre poderia ser portador de pelo menos uma delas. Hoje, em contrapartida, esse discurso ressurge com grande força nas escolas, quase que em oposição ao discurso das dificuldades de aprendizagem, ou seja, uma nova categoria de sujeição dos indivíduos, os intitulados gifted.

Nesse período, aconteceu, dentro da área da Educação Especial, um descolamento definitivo das práticas relacionadas às altas habilidades daquelas voltadas, até então, para o atendimento de deficientes. Deu-se a aprovação do Plano Nacional de Educação ${ }^{l l}$, determinando a implantação do atendimento das crianças com altas habilidades/superdotação e a divulgação das Diretrizes Nacionais da Educação Especial na Educação Básica.

É nos primeiros anos do século XXI que o discurso das altas habilidades - constituído de enunciados científicos e psicopedagógicos - ganha destaque,

\footnotetext{
${ }^{7}$ Datada de 1986. Reeditada em 1995, atualizada e enriquecida não só na terminologia, mas também em seu conteúdo.

${ }^{8}$ De 1994, a Declaração de Salamanca proclama que toda criança tem direito fundamental à educação e lhe deve ser dada a oportunidade de atingir e manter um nível adequado de aprendizagem; toda criança possui características, interesses, habilidades e necessidades de aprendizagem que são únicas; sistemas educacionais deveriam ser designados e programas educacionais deveriam ser implementados no sentido de se levar em conta a vasta diversidade de tais características e necessidades; aqueles com necessidades educacionais especiais devem ter acesso à escola regular, que deveria acomodá-los dentro de uma pedagogia centrada na criança, capaz de satisfazer a tais necessidades. ${ }^{9}$ Ocorrido em 1993.

${ }^{10}$ Como colocado anteriormente, ocorreu em 1995 e tem como objetivo adequar terminologia e ações ligadas a esses indivíduos.

${ }^{11}$ Lei 10.172 de 2001.
} 
mais precisamente em 2003, com a criação do Conselho Brasileiro para a Superdotação (Consbrad) e em 2005, quando o MEC criou, em todos os 26 estados e no Distrito Federal, Núcleos de Atividades de Altas Habilidades/ Superdotação (NAAH/S) para dar um atendimento mais qualificado aos ditos portadores de altas habilidades. Tal ação teve a parceria da UNESCO e do FNDE.

Como movimentação mais recente no campo das políticas públicas, temos a publicação da Política Nacional de Educação Especial na perspectiva da Educação Inclusiva, que esclarece que os educandos portadores de altas habilidades terão atendimento especializado ao longo da escolaridade; e, ainda, o decreto ${ }^{12}$ que determina de que forma vai acontecer esse atendimento especializado e que a responsabilidade técnica e financeira será do MEC.

Por fim, e não menos importante, a Resolução CNE/CEB No 4/2010 esclarece que os sistemas de ensino são responsáveis por matricular os alunos com altas habilidades/superdotação nas classes comuns do ensino regular, bem como em um Atendimento Educacional Especializado (AEE). Tal atendimento pode acontecer nas salas de recursos multifuncionais ou em centros de AEE da rede pública, de centros comunitários, confessionais, ou filantrópicos sem fins lucrativos. Também determina que a identificação desses educandos deve ser feita pelo professor do AEE, que deve dar suporte para que os educadores das classes comuns possam desenvolver todas as potencialidades desses alunos.

De alguma forma, tal resolução veio a formalizar uma prática de seleção de sujeitos portadores de altas habilidades, hoje. Entendendo as altas habilidades como práticas discursivas, para compreender a forma como tais discursos circulam nas escolas atualmente, e capturam sujeitos, temos a contribuição do campo das pesquisas científicas.

Segundo os levantamentos realizados por Pérez e Freitas (2009), no que diz respeito à produção acadêmica, até a década de 70 podemos contabilizar, na área da Educação Especial, mais de 50 publicações sobre a temática das altas habilidades - entre livros, artigos e anais de eventos - contudo, apenas três correspondiam a livros publicados. Nas décadas de 80 e 90 houve uma grande queda nas publicações, visto que temos apenas quatro novos títulos. Todavia, é a partir do ano 2000 que ocorreu o recrudescimento do interesse pelo assunto, de forma que já pudemos contabilizar onze livros publicados nesse período.

Acredito que esse número elevado de publicações acompanhou as movimentações que ocorreram no campo das políticas públicas, visto que foi um

${ }^{12}$ Decreto $n^{\circ} 6571 / 08$ de 2008. 
período em que aconteceram significativas demarcações no campo da educação especial, mais especificamente, relacionadas àqueles que não são os deficientes, mas portadores de outras necessidades especiais.

No que diz respeito à produção científica sobre o tema, busco atualizar o levantamento já realizado por Pérez e Freitas em 2009, incluindo, também, os dados de 2008. De acordo com o Banco de Teses e Dissertações da CAPES ${ }^{13}$, existem apenas nove teses de Doutorado e 57 dissertações de Mestrado defendidas no período de 1987 a 2008 com foco na área das altas habilidades. Podemos perceber que houve uma significativa mobilização científica, tratando das altas habilidades no referido período, e, simultaneamente, as pesquisas científicas e produções acadêmicas pertinentes ao tema, que contavam com um número razoável de publicações antes dos anos 70, foram quase inexistentes. Isso se deu, em parte, pela forma com que o discurso educacional tratava os diferentes - aqueles que não frequentavam a escola regular - bem como eram assujeitados a um discurso que os patologizava e os mantinha à margem dos discursos educacionais.

Nas décadas de 80 e 90, período em que se iniciaram as grandes discussões na esfera da inclusão dos diferentes na escola regular, já se observava alguma produção científica sobre o tema. Na segunda metade da década de 90 , essa tendência ganhou força, sendo desencadeada por discussões de abrangência nacional e internacional.

No século XXI, percebemos um ressurgimento desse discurso, reatualizado pelas discussões e estudos realizados a partir de encontros e congressos da área. As pesquisas científicas foram acompanhadas pela grande produção acadêmica, assim como, pelas mais significativas legislações. Nos primeiros anos desse século foi promulgado o Plano Nacional de Educação, as Diretrizes Nacionais da Educação Especiais, bem como a implantação dos Núcleos de Atividades, os quais demarcaram e regraram a forma como se deve dar a identificação e o trabalho com os indivíduos portadores de altas habilidades.

Atualmente, não existe um consenso acerca do termo adequado para designar tais sujeitos, pois, em referências europeias, temos o termo altas habilidades; na Austrália, a preferência recai no uso do termo habilidades especiais; em referências norte-americanas, experts - que tem diferentes traduções, como superdotados ou mais capazes - e gifted ou giftedness - que pode ser traduzido como talentoso, dotado.

\footnotetext{
${ }^{13}$ A referida pesquisa foi realizada a partir de buscas com as palavras-chave altas habilidades, superdotação, superdotado e gifted.
} 
O MEC, por sua vez, adota o termo portador de altas habilidades/ superdotação, acentuando o caráter comportamental e diferenciando o portador dessa característica dos demais não enquanto pessoa, mas enquanto comportamento (ALENCAR; FLEITH, 2001). Neste estudo, de forma geral, optamos por usar o termo altas habilidades para nos referirmos a tal característica.

Existe, ainda, uma diferença no entendimento da superdotação e do talento estabelecida por autores norte-americanos e europeus, e que está ligada a uma hierarquização dos saberes. Para eles, a superdotação está ligada às altas habilidades nas áreas linguística e lógico-matemática; enquanto o talento está ligado às altas habilidades em outras áreas, como a musical, a interpessoal e a corporal-cinestésica, por exemplo (PÉREZ, 2003). Sendo as áreas linguística e lógico-matemática os campos do conhecimento mais valorizados pelo discurso pedagógico, faz sentido essa diferenciação, bem como a sua associação com o termo superdotação.

Dentre o que se tem dito sobre isso, para o MEC/SEESP (BRASIL, 1995a), ser portador das altas habilidades significa apresentar um desempenho superior ao da média, em uma área do conhecimento ou em áreas combinadas. Contudo, tal desempenho deve estar atrelado à criatividade e ao intenso envolvimento do indivíduo na área à qual ele se destaca. Assim, conforme discussão posterior, o pertencimento a esse grupo está ligado a três fatores principais: habilidade acima da média, criatividade e envolvimento intenso e afetivo com a área de interesse.

No que tange as características desses sujeitos, o Centro para el Desarrollo del Alto Potencial, com sede em Buenos Aires, coloca a impossibilidades de buscarmos generalizações acerca das condutas a serem apresentadas por eles; entretanto, defende que tais crianças devem apresentar várias dentre as seguintes características:

- São observadores e curiosos.

- Apresentam uma avançada habilidade para a leitura e a escrita.

- Aborrecem-se com facilidade e podem se mostrar desatentos e frustrados em alguns momentos.

- Podem apresentar longos períodos de concentração quando o assunto lhes interessa.

- Apresentam facilidade no pensamento abstrato e crítico.

- Podem apresentar habilidade ilimitada em apenas uma área do conhecimento.

- Resistem à repetição memorística e a serem somente ouvintes. 
- Têm alta sensibilidade.

- São excessivamente ativos, o que pode ser confundido com uma hiperatividade.

De acordo com Alencar e Fleith (2001), Mate (2000) e Melo (2007), entre outros pesquisadores, os alunos ditos portadores de altas habilidades são, com frequência, tachados como crianças problemáticas, uma vez que não conseguem se adaptar a uma estrutura escolar que pauta seu trabalho para atender a um aluno mediano. Dessa forma, muitos deles apresentam comportamentos de falta de atenção, hiperatividade, ou seja, postura inadequada nas aulas.

A habilidade numérica, a alta memória, a abstração, o pensamento divergente, o raciocínio lógico avançado, a rapidez de pensamento e o desenvolvimento elevado da capacidade mental, de acordo com Maitra e Sharma (apud MELO, 2007) são destacados como características específicas das altas habilidades em Matemáticas.

No Brasil, a avaliação para a identificação de indivíduos com altas habilidades foge do clássico questionário que mede o QI ${ }^{14}$ (Quociente de Inteligência) e investe na aplicação de diferentes testes que avaliam as áreas das múltiplas inteligências descritas pelo psicólogo Howard Gardner, sejam elas: linguística, lógico-matemática, espacial, musical, corporal-cinestésica, interpessoal, intrapessoal e naturalista. Entende-se, ainda, que a inteligência esteja ligada a noções culturais, uma vez que define inteligência como a habilidade para resolver problemas ou criar produtos que sejam significativos num dado ambiente cultural (GARDNER, 2001).

Para Winner (1998, p.13), podemos focalizar a superdotação em duas áreas ligadas à produção científica - linguagem e matemática - e em duas áreas artísticas - artes visuais e música - pois nessas quatro áreas as crianças, via de regra, apresentam altas habilidades. Tal constância se observa em função do fato de tais áreas, além de serem atraentes para as crianças, serem regidas por regras e se apresentarem altamente estruturadas. De acordo com Mate (2000, p.69), o que diferencia as crianças superdotadas das demais é "la velocidad de su maduración intelectual" o que podemos entender como um aprendizado superior num determinado espaço de tempo.

\footnotetext{
${ }^{14}$ O teste de QI foi estruturado por Binet e Simon em 1905, a pedido do Ministro de Instrução Pública da França, e está relacionado com a tradicional visão de inteligência, que valoriza apenas as áreas linguística e lógica. Posteriormente, verificou-se que tal teste é inteiramente influenciado pelo que se aprende e pelo que é ensinado, uma vez que a resposta entendida como certa apenas indicava o conhecimento da criança das informações cobradas ou das situações propostas.
} 
Renzulli (apud ALENCAR; FLEITH, 2001), buscando aprimorar a identificação das altas habilidades, criou o Modelo dos Três Anéis. Segundo ele, o comportamento dos superdotados compreende o pertencimento a três campos comportamentais, simultaneamente: habilidades gerais e/ou específicas acima da média, elevados níveis de comprometimento com a atividade e elevados níveis de criatividade.

Dito de outra forma, podemos dizer que os portadores de altas habilidades são aqueles que se destacam em relação ao seu grupo social, uma vez que evidenciam as capacidades anteriormente citadas. Para o MEC/SEESP,

Alta habilidade refere-se aos comportamentos observados e/ou relatados que confirmam a expressão de "traços consistentemente superiores" em relação a uma média (por exemplo: idade, produção, ou série escolar) em qualquer campo do fazer ou saber (BRASIL, 1995b, p.13).

Assim, se analisarmos tais formulações a partir da perspectiva proposta neste trabalho, podemos perceber esse sujeito das altas habilidades como uma produção discursiva, uma vez que existe uma prática regrada por enunciados políticos e pedagógicos.

Veiga-Neto (2007) esclarece que o discurso e o poder forjam uma trama um tanto interessante, uma vez que os discursos ativam e colocam em circulação os poderes. Contudo, não de forma direta e mecânica, mas de uma forma não linear e dispersa. Segundo as palavras do próprio Foucault:

[...] é preciso admitir um jogo complexo e instável em que o discurso pode ser, ao mesmo tempo, instrumento e efeito de poder, e também obstáculo, escora, ponto de resistência e ponto de partida de uma estratégia oposta. O discurso veicula e produz poder; reforça-o, mas também o mina, expõe, debilita e permite barrá-lo (1993, p.96).

De acordo com Veiga-Neto (2007, p.122), o poder existe a partir das práticas em que ele se manifesta e atua. Dessa forma, o discurso das altas habilidades - bem como a legislação que o regulamenta e as produções acadêmicas e científicas - podem ser vistos como um dispositivo ${ }^{15}$ disciplinar

\footnotetext{
${ }^{15}$ Tal expressão é entendida neste estudo como um conjunto de práticas discursivas, que estabelece regimes de verdade e que visa constituir um tipo específico de sujeito. De acordo com Castro (2009, p.124), o dispositivo é a rede de ligação entre elementos heterogêneos de um discurso, estabelecendo o nexo entre esses elementos, constituindo regimes de verdades. Foucault (2007b, p.244) esclarece que o dispositivo é, essencialmente, uma rede que se pode estabelecer entre os seus elementos, ou seja, entre o dito e o não dito.
} 
na tarefa de normalização, regulação, governo das pessoas e das comunidades. Em se tratando da prática discursiva das altas habilidades, o que temos são relações de poder-saber, uma vez que existem saberes entendidos como superiores no momento de seleção e identificação desses indivíduos.

Os registros documentais que se referem às altas habilidades acabam, sempre, por se balizar nos conceitos de média e de norma, da mesma forma que deixam subentendido que existe um rendimento aceito como normal. Assim, aquelas crianças que apresentam um subrendimento ou um super-rendimento tornam-se um problema para a escola. Para Guenther,

Reconhecer sinais de capacidades e talentos em ambientes escolares tem relação íntima com o sistema de educação regular, o que pode vir a ser uma situação estruturalmente problemática: a instituição escola é voltada para a população geral em termos de "normas", "médias" e "maiorias", e por ideologia mais propensa a corrigir quem está "abaixo da média”, do que em estimular quem já está acima dela (2006, p.41).

Na medida em que temos práticas discursivas acerca de um rendimento ideal, podemos observar diferentes assujeitamentos que são conduzidos por regras de identificação e que obedecem a normas. Para Foucault (2007a, p.36): “A disciplina é um princípio de controle da produção do discurso. Ela lhe fixa os limites pelo jogo de uma identidade que tem a forma de uma reatualização permanente das regras". Diferentemente das teorizações críticas, que acreditavam que o poder distorce e reprime, as teorias pós-estruturalistas defendem o poder para além da esfera disciplinar, mas como algo que constitui, produz, cria identidades ${ }^{16}$ e subjetivações. Temos, então, uma estreita relação entre discurso, poder e governo, uma vez que os dois primeiros subjetivam e, o terceiro - constituído de práticas discursivas - desencadeia relações de poder.

Dean (1999) sustenta que as fontes de poder são diversas, pois

Os que possuem poder podem ser as pessoas, elites, classes governantes, homens, etc., e a legitimidade de seu governo pode estar no estado de direito, na hegemonia de classe, nas ideologias dominantes, no consentimento dos governados, na cultura patriarcal, etc (p. 24).

\footnotetext{
${ }^{16}$ A noção de identidade que está sendo considerada aqui tem como base os pressupostos da viradalinguística que considera tais identidades a partir dos reconhecimentos por semelhança ou, ainda, por familiaridade, mais facilmente detectada pela não-identidade - não num sentido de reconhecimento pela exclusividade no idêntico, como argumentava Deleuze (VEIGA-NETO; LOPES, 2007a, p. 29).
} 
Corazza, por sua vez, chama a atenção para a impossibilidade de não estar vinculados a relações de poder no ambiente escolar, pois para ela:

Não existe mais a posição privilegiada do educador/ educadora, a partir do qual se pode criticar o poder sem se estar envolvido/a com ele. O objetivo já não será mais buscar uma situação de não-poder, mas um estado permanente, sem fim, de luta contra todas as posições de poder, incluindo principalmente aquelas nas quais nós próprios/ as estamos mergulhados/as (1998, p.3).

Considerando que não podemos ignorar a existência de relações de poder na educação - visto que a escola articula os poderes que nela circulam, assim como, os saberes que a compõe - temos que atentar para o fato de que nas dinâmicas escolares também se presentificam estratégias de luta, reação e resistência.

No trabalho específico com as altas habilidades, existem diferentes guias produzidos pelo MEC, os quais estão baseados em leis, resoluções etc., que direcionam o trabalho com essas crianças. Poder viabilizar esse trabalho, algumas vezes, caracteriza-se por atos de resistência - em relação às normas burocráticas ou, ainda, em relação ao posicionamento dos docentes.

Por conseguinte, como afirma Dean, “Os governados são livres uma vez que são atores, isto é, é possível agirem e pensarem de diversas formas e às vezes de formas não previstas pelas autoridades" (1999, p.13). Assim, as práticas de resistência podem ser entendidas como uma maneira de se diferenciar frente aos discursos, uma forma diferente de se assujeitar a uma relação de poder e que não se caracteriza, necessariamente, como antítese do poder.

São essas múltiplas relações de poder dentro das instituições sociais que proporcionam as condições para que se forjem indivíduos disciplinados e normatizados, ou seja, sujeitos assujeitados a discursos que buscam nada mais do que uma gestão controlada de todo um corpo social.

Penso que esses conceitos nos auxiliam a elaborar as lutas contra as diferentes formas de assujeitamento e captura de identidades. Tais lutas estão ligadas às possibilidades de resistência à forma como os discursos constituem os indivíduos, fazem-nos pensar, agir e ser. Ou seja, da forma como as relações de poder podem vir a sustentar verdades no âmbito escolar, ou melhor, nas atividades relacionadas às altas habilidades.

Baseado nas relações entre poder-saber-verdade, "Foucault insistirá em que não há verdade fora do poder ou sem o poder, pois toda verdade gera 
efeitos de poder e todo poder se ampara e se justifica em saberes considerados verdadeiros" (DUARTE, 2009, p.46). Tal afirmação vem ao encontro de uma preocupação que permeia este trabalho: a seleção dos indivíduos ditos com altas habilidades em matemática. De acordo com os documentos oficiais, existe um parâmetro de normalidade para identificação desses educandos portadores de altas habilidades, contudo, tais documentos também buscam enfatizar que não existe um padrão de características comuns entre eles. Ou seja, mesmo que existam características comuns, a seleção se dá de uma forma singular e pontual.

De acordo com os documentos do MEC/SEESP que embasam essa prática discursiva, cada indivíduo tem "um perfil próprio e uma trajetória singular de realizações" (BRASIL, 2007, p.14). Assim, podemos dizer que um indivíduo tem altas habilidades, por exemplo, em matemática apenas no contexto em que ele vive e não em outro?

Winner tenta esclarecer um pouco melhor esta ideia, afirmando que As crianças superdotadas não são apenas mais rápidas do que as crianças normais, mas são também diferentes. Porque requerem apoio estruturado mínimo, porque fazem descobertas sozinhas e inventam novas formas de entender e porque têm tamanha fúria por dominar, elas são diferentes das crianças que apenas trabalham com afinco extremo (1998, p. $247-248)$.

A forma como algumas crianças constroem sua própria lógica de cálculo e raciocínio pode influenciar na forma de fazer matemática da escola, o que pode culminar com o não sucesso escolar. Algumas crianças parecem induzir as regras da matemática, precisando de intervenção mínima, restrita apenas ao esclarecimento das questões que afloram. É como se elas intuíssem as regras da matemática e criassem uma forma própria de lidar com elas.

Uma possibilidade que podemos estar levantando, frente a essa perspectiva teórica, é que o efeito gerado por essas relações de poder é um controle baseado em normas, regras e padrões, instituídos pelos discursos correntes na sociedade. Cabe colocar que tais normas produzem verdades e desencadeiam formas de subjetivação, o que, sumariamente, pode ser entendido como um processo inventivo.

Frente a isso, podemos perceber a presença de um modelo normativo, dado que a sociedade entende que existe uma prática matemática adequada. A escola solicita de seus educandos a resolução de problemas através de modelos e, habitualmente, não valoriza a criatividade, bem como a experimentação de 
diferentes estratégias de solução dos mesmos. Da mesma forma que não permite uma liberdade de experimentação de raciocínios diferentes daqueles já esperados.

Segundo Loponte (2003, p.70): “Acreditamos na verdade prometida pela ciência, na soberania da razão, somos otimistas teóricos, utilitaristas, acreditamos que há verdades por trás das aparências". Dito de outra forma, acreditamos na existência de uma norma, na crença da existência de uma matemática verdadeira, que neste caso é aquela ensinada pela escola.

Tal norma à qual me refiro não é a conhecida norma disciplinar - que nos remete a adestramentos do corpo e da alma - mas, sim, a uma ação normal entre os educadores em aceitar como verdadeira apenas a matemática acadêmica, o que podemos chamar de normalização.

Foucault esclarece tal ideia, quando nos coloca que:

A norma está em jogo no interior das normalidades diferenciais. O normal é que é primeiro, e a norma se deduz dele, ou é a partir desse estudo das normalidades que a norma se fixa e desempenha seu papel operatório. Logo, eu diria que não se trata mais de uma normação, mas sim, no sentido estrito, de uma normalização (2008, p.83).

Tal norma, segundo ele, é identificada a partir das práticas normalizadoras, ou seja, ela é anterior à normalização e acaba por diferenciar os normais dos anormais, mantendo, com todos, uma relação. Como explicam Veiga-Neto e Lopes (2007b, p.956), é no fato de a norma ser anterior ao processo de normalização - ser fundante - que ela ganha um status demasiadamente natural.

A escola é o lugar de embate entre esses dois conceitos: norma e normalização. O primeiro remete-nos a uma norma disciplinar, que diz respeito à correção dos corpos e dos indivíduos, à modelagem do aluno que não sabe; enquanto o segundo nos remete a uma quantificação estatística, que aponta para a ação de uma sociedade de controle, que visa produzir médias a partir do levantamento de problemas, objetivando manter todos os alunos sob um curso normal que se acredita existir.

Assim, a escola mais uma vez ganha destaque nesse contexto de pesquisa. Além de beneficiar a manutenção de discursos específicos, é na escola que a normalização ganha destaque, pois, ainda segundo Veiga-Neto e Lopes,

[a escola] funcionou - e continua funcionando - como um lugar privilegiado para a invenção e experimentação dos novos saberes e para a intervenção do Estado e de suas políticas que visam à segurança da população (2007b, p.957 -958). 
Podemos perceber, também, em meio à prática discursiva das altas habilidades, a presença de uma ação de normalização, uma vez que tais educandos são identificados a partir de uma norma padronizada pelo sistema de ensino. $\mathrm{Ou}$ seja, tais alunos se destacam em relação a um padrão presente nas escolas; por vezes, os educandos que apresentam altas habilidades do tipo superdotação escolar destacam-se positivamente em relação à média, enquanto aqueles que apresentam superdotação criativo-produtiva destacam-se negativamente em relação a ela.

De acordo com as teorias de Renzulli (apud VIRGOLIM, 1997, p.181), uma criança pode se encaixar em duas categorias de altas habilidades: a superdotação escolar e a superdotação criativo-produtiva. A primeira se refere àqueles indivíduos que apresentam facilidade de "aprendizagem dedutiva, treinamento estruturado nos processos de pensamento, e aquisição, estoque e recuperação da informação", ou seja, são aqueles educandos que tiram boas notas na escola e que podem apresentar um alto QI. Os indivíduos que apresentam habilidade criativo-produtiva são aqueles que se envolvem no "desenvolvimento de materiais e produtos originais", sendo que a ênfase é colocada no uso e na aplicação dos conhecimentos e "nos processos de pensamento de forma integrada, indutiva, e orientada para os problemas reais", dessa forma, são aqueles alunos que conseguem se envolver com as tarefas que lhe são desafiadoras. As habilidades desse grupo de crianças podem passar despercebidas pelos professores em função de não estarem associadas a um alto rendimento.

É importante ressaltar que os indivíduos que normalmente acabam sendo identificados como portadores de altas habilidades são aqueles que pertencem à categoria da superdotação escolar, uma vez que obtêm sucesso na escola e, consequentemente, são identificados com mais facilidade. Ou ainda, como sugere equivocadamente o termo superdotado, são relacionados por seus educadores a superalunos. Cabe destacar que as mais variadas instituições de apoio a esses indivíduos, bem como pesquisadores como Guenther (2006), Gardner (2001) e Virgolim (1997) acreditam que a avaliação dos indivíduos deve ser baseada em múltiplos instrumentos - de caráter formal e informal, assim como observações - buscando-se ter uma visão integral dos mesmos.

Segundo as diretrizes do MEC/SEESP (BRASIL, 1995a, p.23), a identificação dos portadores de altas habilidades/superdotação pode ser realizada em qualquer momento da escolarização, contudo, quanto mais breve ocorrer, maiores possibilidades de desenvolvimento o educando terá. Além disso, existe uma facilidade maior de se localizar esses sujeitos até os primeiros anos de 
escolarização, pois ainda são atendidos num sistema de unidocência, o que permite um maior conhecimento por parte do professor.

Em relação aos métodos sugeridos para tal identificação, essas diretrizes apontam que deve se utilizar pelo menos dois instrumentos dentre os seguintes:

- avaliação realizada por professores, especialistas e supervisores;

- percepção de resultados escolares superiores aos demais;

- auto-avaliação;

- aplicação de testes individuais, coletivos ou combinados; e

- demonstração de habilidades superiores em determinadas áreas.

No mesmo documento, a seguinte ressalva é feita:

É da maior importância que, para a identificação dos portadores de altas habilidades/superdotados, sejam observadas as seguintes recomendações:

- deverão ser utilizados para seu diagnóstico testes individuais e/ou coletivos que ofereçam garantia de rigor científico e adequabilidade, e

- deverão ser aplicados, por profissional especificamente preparado, diversos meios e recursos nesse processo (BRASIL, 1995a, p.26).

É interessante atentar para o fato de que tais diretrizes não orientam ou esclarecem como devem ser esses testes, bem como de que forma pode-se garantir o rigor científico. De acordo com esse documento (BRASIL, 1995a, p.26), a escolha da técnica e dos testes a serem utilizados deve corresponder às condições que o serviço de diagnóstico ofertar, bem como do conhecimento dos profissionais envolvidos. Um breve encaminhamento também é dado, no sentido de que se atenda às diferenças individuais e culturais dos educandos quando em processo de identificação, procedendo-se adaptações aos instrumentos, a fim de que se evitem distorções nos resultados.

Para se proceder a um processo qualitativo de identificação, sugere-se uma combinação entre as técnicas de observação ${ }^{17}$ - por parte dos professores ou pais - com a aplicação de testes individuais ou coletivos e com a avaliação do desempenho dos educandos envolvidos neste processo. Visando a uma avaliação ampla dos indivíduos, o MEC/SEESP (BRASIL, 2007, p.58 - 62) sugere as seguintes alternativas: nomeação por professores, indicadores de criatividade, nomeação por pais, nomeação por colegas, autonomeação, nomeações especiais

\footnotetext{
${ }^{17}$ As diretrizes do MEC/SEESP (BRASIL, 1995a) apontam para alguns aspectos importantes que devem ser observados na indicação de um educando.
} 
(por professores de anos anteriores, por exemplo), avaliação dos produtos, escalas de características e listas de observação, e nomeação por motivação do aluno.

Para Guenther (2006, p.78), a pergunta "Essa criança é, ou não é, superdotada?" perdeu embasamento a partir do acréscimo de novos fatores na identificação das crianças talentosas, e deixou de ser a questão chave no campo da educação especial. Passou a ser substituída por questões mais abrangentes do tipo "De que maneiras, e por quais caminhos é possível reconhecer sinais de que uma criança tem potencial maior que a média da população comparável, o que acarreta necessidades especiais em educação?".

Vieira (2005, p.168-169), através de suas pesquisas no campo das altas habilidades, estrutura uma proposta de avaliação desses alunos a partir de quatro aspectos fundamentais. $\mathrm{O}$ primeiro diz respeito à mobilidade dos instrumentos de coleta de dados e identificação desses indivíduos, uma vez que não podemos desconsiderar os fatores ambientais e a predisposição dos educandos no envolvimento com a atividade.

O segundo aspecto defende uma consonância entre os meios de avaliação e as formas de intervenção dos profissionais envolvidos no processo, pois os fatores afetivos envolvidos podem influenciar os modos de ver, ouvir e analisar os dados levantados. Cabe destacar que tal aspecto está em estreita relação com as práticas discursivas em circulação nesses ambientes escolares.

O terceiro aspecto - e mais interessante - está relacionado à perspectiva ecológica da avaliação, a qual considera as possibilidades de uma associação com o ambiente e as atividades naturais dos educandos, como por exemplo, as brincadeiras de criança.

Por fim, o quarto defende um acompanhamento e uma reavaliação contínua desses aspectos, esclarecendo a importância de se garantir o acompanhamento sistemático dos sujeitos ao longo dos anos em diferentes situações escolares e extraescolares nas quais estão envolvidos.

Faz-se fundamental para este estudo esclarecer o terceiro aspecto, visto que ele nos remete às situações do cotidiano dessas crianças. De acordo com Vieira,

[...] está relacionado ao que Ramos-Ford e Gardner (1991) caracterizam como perspectiva ecológica, pois, ao experimentarem situações vinculadas ao seu dia-a-dia e com materiais (re)conhecidos, as crianças tiveram a oportunidade de demonstrar sua compreensão nas diferentes questões surgidas na interação com os colegas e com os brinquedos, possibilitando diferentes respostas a estas situações (2005, p.169). 
Torna-se evidente que existe uma vinculação entre a estrutura das atividades de seleção e um possível resultado afirmativo nas mesmas. Dessa forma, me parece prudente colocar em suspenso a expressão portador de altas habilidades, uma vez que receio que a superdotação, assim como colocam Alencar e Fleith (2001), não está no indivíduo, mas na sua relação com o meio.

De acordo com elas,

[...] há autores que propõem inclusive que superdotação não é algo que o indivíduo tem ou não tem, considerando antes este conceito como relativo e situacional. Desta forma, um determinado indivíduo poderia ser considerado superdotado em uma determinada situação e não em outra. (p.58).

Outra questão fundamental a se considerar, neste estudo, é a forma como os educadores entendem as altas habilidades, pois é a partir desse posicionamento que se dará o processo de seleção desses sujeitos. Tal entendimento está relacionado às verdades colocadas em circulação pelas práticas discursivas, bem como pelas relações de poder-saber relacionadas a elas.

De acordo com Foucault (2003, p.27), as condições políticas e econômicas de existência acabam por formar os sujeitos do conhecimento e, consequentemente, as relações de verdade. Sendo o indivíduo sujeito de verdades e saberes propagados pelos discursos, precisamos entender como estão se constituindo os sujeitos que interessam a esse estudo, ou ainda, compreender quais indivíduos estão em evidência a partir de estratégias de poder-saberverdade presentes nos discursos. Sendo assim, pode-se falar de uma identidade gifted, porque existe um processo de identificação de subrendimento, sustentada pelo discurso das altas habilidades.

Veiga-Neto e Lopes (2007a, p.29) argumentam que, o mesmo que acontece com o significado das palavras acontece com o significado do termo identidade, pois ele é determinado nas dinâmicas das vidas e dos usos que fizermos dela. Considerando que as identidades são dadas por relações de semelhança, tais atributos de semelhança/familiaridade são elencados e detectados por nós, ou seja, não existe uma relação de auto-identidade. Consequentemente, não se tem como ignorar que as mesmas se formam e se instituem alicerçadas em relações de poder.

Ainda, de acordo com Veiga-Neto e Lopes, 
O que no máximo se pode fazer é uma lista de propriedades e atributos definidores de uma identidade; mas essa será sempre uma lista arbitrária, determinada social e culturalmente e expressa linguisticamente. Somos nós que atribuímos os atributos... E isso se dá em complicados processos competitivos e disputas por imposição de sentido... Assim, aquela será sempre uma lista contingenciada por relações de poder (2007a, p.29).

Dessa forma, podemos entender as altas habilidades como uma identidade presente nas práticas discursivas escolares, uma vez que as atitudes esperadas desses sujeitos foram elencadas a partir do que se entende como características. Assim, acreditamos que a alta habilidade não está na criança, mas que a mesma é assujeitada por esse discurso.

Essas práticas discursivas relacionam-se com o que Foucault (1995, p.236) sugere em relação às possibilidades de "submissão da subjetividade", visto que as relações de poder existem de forma pulverizada e se relacionam com as formas de assujeitamento dos indivíduos. No que tange à constituição de identidades, Deleuze (2006, p.113) esclarece que uma das formas de sujeição que se faz presente em nosso cotidiano é aquela que "consiste em ligar cada indivíduo a uma identidade sabida e conhecida, bem determinada de uma vez por todas".

Da mesma forma, podemos analisar o papel dos processos de seleção e identificação dos sujeitos com altas habilidades enquanto dispositivos de controle, tendo como base tanto o dito quanto o não dito. Cabe colocar que tal processo constitui um conjunto de práticas discursivas que coloca em movimentação determinados regimes de verdade, os quais estão em conexão com as relações de poder que permeiam esse tempo e espaço. Além disso, podemos dizer que se fundam enquanto dispositivo por constituir um tipo específico de sujeito, o sujeito das altas habilidades.

Partindo do princípio de que o contexto social não é apenas um cenário, mas sim um elemento constitutivo de nossa forma de pensar, é a partir dele que temos a constituição de práticas sociais específicas. Assim, falar sobre educação é falar de prática social, a qual, por sua vez, nos leva a falar do sujeito. A prática social tem estreita relação com os discursos que a constitui, e, sendo o sujeito aquele que está no discurso, estamos inevitavelmente falando dele.

Por fim, o objetivo deste trabalho não tem sido descobrir o que está por trás do discurso das altas habilidades em matemática, muito menos descobrir 
algo novo, mas sim tencionar o pensamento sobre essa temática, compreender tal discurso da forma que está posto nas escolas hoje, bem como compreender quais as condições de possibilidade para que ele ressurja e se mantenha nas escolas atualmente. Dito de outra forma, deseja-se problematizar esse discurso, analisar, conforme sugere Foucault (2004, p.242), as práticas discursivas e não discursivas que colocam em jogo as verdades que constituem as altas habilidades nos ambientes escolares na contemporaneidade.

\section{Referências}

ALENCAR, E. M.; FLEITH, D. de S. Superdotados: determinantes, educação e ajustamento. 2. ed. São Paulo: EPU, 2001.

BELLO, S. E. Jogos de linguagem, práticas discursivas e produção de verdade: contribuições para a Educação (Matemática) contemporânea. Zetetiké, Campinas, v.18, Número Temático de 2010, p. 545-588, 2010.

BRASIL. Ministério da Educação e do Desporto. Secretaria de Educação Especial. Altas habilidades/superdotação: encorajando potenciais. VIRGOLIM, A. M. R. Brasília: MEC/SEESP, 2007.

BRASIL. Ministério da Educação e do Desporto. Secretaria de Educação Especial. Subsídios para a organização e funcionamento de serviços de educação especial. Brasília: MEC/SEESP, 1995a.

BRASIL. Ministério da Educação e do Desporto. Secretaria de Educação Especial. Diretrizes gerais para o atendimento educacional aos alunos portadores de altas habilidades/ superdotação e talentos. Brasília: MEC/SEESP, 1995b.

CASTRO, E. Vocabulário de Foucault: um percurso pelos seus temas, conceitos e autores. Tradução de Ingrid M. Xavier. Belo Horizonte: Autêntica, 2009.

CORAZZA, S. M. Temas Culturais: um modo de luta curricular. Panambi: 1998. Palestra concedida no $7^{\circ}$ Seminário Municipal e no $4^{\circ}$ Seminário Regional de Educação. 03 ago. 1998.

DEAN, M. Governmentality: power and rule in modern society. Tradução de Ricardo Uebel. London: Sage, 1999.

DELEUZE, G. Foucault. Tradução de Claudia S. Martins. São Paulo: Brasiliense, 2006. 
DUARTE, A. Dossiê Michel Foucault. Revista Cult, São Paulo, n. 134, p. 43-64, abr. 2009.

FOCAULT, M. Segurança território, população. Tradução de Eduardo Brandão. São Paulo: Martins Fontes, 2008. (Coleção Tópicos).

FOUCAULT, M. A ordem do discurso. Tradução de Laura F. Sampaio. 15. ed. São Paulo: Edições Loyola, 2007a.

FOUCAULT, M. Microfísica do Poder. Tradução de Roberto Machado. 24. ed. Rio de Janeiro: Edições Graal, 2007b.

FOUCAULT, M. O cuidado com a verdade. In: FOUCAULT, M. (Org.). Ditos e escritos V: Ética, sexualidade, política. Rio de Janeiro: Forense Universitária, 2004. p.240- 251 .

FOUCAULT, M. Conferência 1. In: FOUCAULT, M. (Org.). A verdade e as formas jurídicas. Rio de Janeiro: Nau, 2003. p.7-27.

FOUCAULT, M. O sujeito e o poder. In: RABINOW, P.; DREYFUS, H. Michel Foucault: uma trajetória filosófica. Para além do estruturalismo e da hermenêutica. Tradução de Vera Porto Carrero.Rio de Janeiro: Forense Universitária, 1995. p. 229-250.

FOUCAULT, M. História da Sexualidade I: A Vontade de Saber. Rio de Janeiro: Edições Graal, 1993.

GARDNER, H. Inteligência: um conceito reformulado. Rio de Janeiro: Objetiva, 2001.

GUENTHER, Z.C. Capacidade e Talento: um programa para a escola. São Paulo: EPU, 2006.

LOPONTE, L. Do Nietzsche trágico ao Foucault ético: sobre estética da existência e um ética para a docência. Educação e Realidade, Porto Alegre, v.28, n.2, p. 69 - 82, jul./ dez. 2003.

MACHADO, R. Nietzsche e a verdade. São Paulo: Edições Graal, 2002.

MATE, Y. B. Problemática del niño superdotado. 3. ed. Salamanca: Amarú Ediciones, 2000 .

MELO, M. A. F. Altas Habilidades/Superdotação em Matemática. Boletim da

Faculdade Jesus Maria José, Taguatinga, p. 1-3, out. 2007. 
MOSÉ, V. A palavra como verdade. In: MOSÉ, V. (Org.). Nietzsche e a grande política da linguagem. Rio de Janeiro: Civilização Brasileira, 2005. p. 70 - 86.

PÉREZ, S. G. P. B. Mitos e crenças sobre as pessoas com altas habilidades: alguns aspectos que dificultam o seu atendimento. Revista Educação Especial, São Paulo, v. 22, n. 2, p. 45-59, 2003.

\section{PÉREZ, S. G. P. B.; FREITAS, S. N. Estado do conhecimento na área de altas}

habilidades/superdotação no Brasil: uma análise das últimas décadas. 2009, 32. , Reunião Anual da ANPED, Caxambu, 2009. Disponível em: <http://www.anped.org.br/ reunioes/32ra/arquivos/trabalhos/ GT15-5514-Int.pdf>. Acesso em: 02 mar. 2010.

VEIGA-NETO, A. Foucault e a Educação. Belo Horizonte: Autêntica, 2007.

VEIGA-NETO, A.; LOPES, M.C. Identidade, cultura e semelhança de família: as contribuições da virada lingüística. In: BIZARRO, R. (Org.). Eu e o outro: Estudos Multidisciplinares sobre Identidade(s), Diversidade(s) e Práticas Interculturais. Porto: Areal, 2007a. p.19-35.

VEIGA-NETO, A.; LOPES, M.C. Inclusão e governamentalidade. Educação e Sociedade, Campinas, v. 28, n. 100, p. 947-964, out. 2007 b.

VIEIRA, N.J.W. Viagem a "Mojave-Óki!"': a trajetória na identificação das altas habilidades/superdotação em crianças de quatro a seis anos. 2005. 315f. Tese (Doutorado em Educação) - Faculdade de Educação, Universidade Federal do Rio Grande do Sul, Porto Alegre, 2005.

VIRGOLIM, Â. M. R. O indivíduo superdotado: história, concepção e identificação. Psicologia: teoria e pesquisa, Brasília, v.13, n.1, p.173-183, jan./abr. 1997.

WINNER, E. Crianças superdotadas: mitos e realidades. Tradução de Sandra Costa. Porto Alegre: Artmed, 1998.

Submetido em Abril de 2012. Aprovado em Junho de 2012. 